\title{
Gastric Neuroendocrine Tumor pM1c TNM Finding v8
}

National Cancer Institute

\section{Source}

National Cancer Institute. Gastric Neuroendocrine Tumor pM1c TNM Finding v8. NCI Thesaurus. Code C135033.

Gastric neuroendocrine tumor with both hepatic and extrahepatic metastases. (from AJCC 8th Ed.) 